\title{
Síntese de éster de cadeia longa via catálise básica heterogênea (Synthesis of long chain ester by heterogeneous base catalysis)
}

\author{
D. S. Moraes*, G. N. R. Filho, J. R. Zamian \\ UFPA - Universidade Federal do Pará, Instituto de Ciências Exatas e Naturais, Faculdade de Química, 66075 - 110, Belém, PA., e-mail: \\ *dorsan@ufpa.br
}

\begin{abstract}
RESUMO: Um éster de cadeia longa foi sintetizado pela transesterificação do palmitato de metila com álcoois de cadeia longa usando óxido de magnésio como catalisador. Esses foram preparados pela decomposição térmica de diferentes precursores, buscando estabelecer relações entre propriedades estruturais e atividades. Temperatura e quantidade de catalisador foram variados para se avaliar o rendimento do éster em função do precursor utilizado na preparação do óxido.
\end{abstract}

Palavras-chave: Transesterificação, ésteres de cadeia longa e óxido de magnésio.

\section{Introduction}

Nos últimos anos, a diminuição das reservas e os constantes aumentos nos preços dos óleos minerais, além de questões ambientais, têm levado muitos pesquisadores a buscarem rotas de síntese que utilizem produtos naturais que sirvam como alternativa para substituição daqueles insumos. Já existem processos que utilizam uma série de substâncias renováveis como o açúcar, o amido, a celulose, os óleos e as gorduras de origem animal e vegetal, dentre muitas outras. Neste contexto, as gorduras e os óleos se destacam, pois podem servir como fonte de matérias-primas e produtos diversificados, semelhante à indústria petroquímica atual. Por exemplo, ésteres de cadeia longa podem ser obtidos tendo como insumos básicos ácidos graxos e álcoois obtidos de óleos vegetais, portanto de fonte renovável. Estes ésteres, conhecidos também como ceras, podem ser utilizados na química fina, entrando na formulação de cosméticos, produtos farmacêuticos e aditivos alimentares. Além disso, podem ser utilizados como lubrificantes especiais, pois sua viscosidade sofre pequena alteração em um amplo intervalo de temperatura.

Nesse processo, catalisadores homogêneos ácidos ou básicos são comumente utilizados. Mas muitas vezes, é comum buscar-se catalisadores heterogêneos que possam apresentar desempenho semelhante aos homogêneos, uma vez que em processos de maior escala, os catalisadores heterogêneos apresentam algumas vantagens, como facilidade de separação e possibilidade de reutilização. Dados da literatura relacionam que hoje se conhecem mais de trezentos tipos de sólidos ácidos ou básicos que foram desenvolvidos como catalisadores nos últimos 40 anos, demonstrando com isso o grande interesse nessa área de pesquisa [1]. Dentre esses, vários óxidos de metais do grupo 2 da Tabela Periódica, tais como $\mathrm{CaO}$, MgO e $\mathrm{BaO}$ que antes eram considerados como materiais cataliticamente inertes à baixas temperaturas, passaram a ser pesquisados em virtude de seu elevado potencial catalítico em certas reações orgânicas, quando apropriadamente ativados [2]. Em particular o MgO pode ser considerado como material de referência em catálise básica heterogênea [3]. 
O MgO pode ser preparado pela decomposição térmica de diferentes precursores, porém mesmo que cada precursor seja tratado nas mesmas condições, é visto que o óxido apresenta diferentes valores de algumas propriedades texturais, como área específica, volume, diâmetro e distribuição de poros, propriedades estas que podem influenciar na atividade do catalisador.

Assim, este trabalho procurou unir as vantagens de se utilizar matérias-primas renováveis (que podem ser obtidas a partir de óleos vegetais) e catalisadores heterogêneos (óxido de magnésio) para se obter produtos (ésteres de cadeia longa) que reconhecidamente tem ampla aplicação. [4, 5, $6]$.

\section{Materiais e métodos}

\section{Síntese dos catalisadores}

Os óxidos foram obtidos a partir da calcinação do $\mathrm{Mg}(\mathrm{OH})_{2}$, do $\mathrm{MgC}_{2} \mathrm{O}_{4}$ e do $\left(\mathrm{MgCO}_{3}\right)_{4}$. $\mathrm{Mg}(\mathrm{OH})_{2} .5 \mathrm{H}_{2} \mathrm{O}$. O $\mathrm{Mg}(\mathrm{OH})_{2}$ foi preparado por agitação do MgO P.A. (Riedel-deHaën) em água deionizada a temperatura ambiente por $24 \mathrm{~h}$ e posterior secagem a $100{ }^{\circ} \mathrm{C}$ em estufa [7]; o $\mathrm{MgC}_{2} \mathrm{O}_{4}$ foi preparado pela mistura de uma solução de $\mathrm{C}_{2} \mathrm{H}_{2} \mathrm{O}_{4} \cdot 2 \mathrm{H}_{2} \mathrm{O} 2 \mathrm{~mol} . \mathrm{L}^{-1}$ aquecida previamente a $40{ }^{\circ} \mathrm{C}$ com uma solução de $\mathrm{C}_{4} \mathrm{H}_{6} \mathrm{MgO}_{4} \cdot 4 \mathrm{H}_{2} \mathrm{O} 2,5$ mol. $L^{-1}$ na mesma temperatura e mantidos sob agitação por mais $5 \mathrm{~min}$ a $40{ }^{\circ} \mathrm{C}$ pois após a mistura das soluções observa-se um ligeiro resfriamento do meio, filtra-se a mistura a vácuo e lava-se o oxalato de magnésio formado com água deionizada até que o filtrante atinja $\mathrm{pH}$ aproximadamente igual a 7 , seca-se o sólido por $12 \mathrm{~h}$ em estufa à $80{ }^{\circ} \mathrm{C}[7,8]$; para o $\left(\mathrm{MgCO}_{3}\right)_{4} \cdot \mathrm{Mg}(\mathrm{OH})_{2} \cdot 5 \mathrm{H}_{2} \mathrm{O}$ foi utilizado o composto P.A. da marca Aldrich. Duas rotas de calcinação dos precursores foram realizadas, a primeira obedecendo condições experimentais encontradas na literatura onde para o $\mathrm{Mg}(\mathrm{OH})_{2}$, e $\mathrm{MgC}_{2} \mathrm{O}_{4}$ a temperatura de calcinação foi de $600{ }^{\circ} \mathrm{C}$ e do $\left(\mathrm{MgCO}_{3}\right)_{4} \cdot \mathrm{Mg}(\mathrm{OH})_{2} \cdot 5 \mathrm{H}_{2} \mathrm{O}$ a $650{ }^{\circ} \mathrm{C}$ (os precursores após sua mudança de fase foram codificados como MgO-2, MgO-4 e MgO-6 respectivamente) por $2 \mathrm{~h}$ com razão de aquecimen- to de $4{ }^{\circ} \mathrm{C} / \mathrm{min}$ partindo da temperatura ambiente $[7,9]$. A segunda rota de calcinação obedeceu os resultados da análise térmica efetuada nos precursores e que monitoraram a temperatura de formação dos óxidos, onde obteve-se $420{ }^{\circ} \mathrm{C}$ para o $\mathrm{Mg}(\mathrm{OH})_{2}, 540{ }^{\circ} \mathrm{C}$ para o $\mathrm{MgC}_{2} \mathrm{O}_{4}$ e $530{ }^{\circ} \mathrm{C}$ para o $\left(\mathrm{MgCO}_{3}\right)_{4} \cdot \mathrm{Mg}(\mathrm{OH})_{2} \cdot 5 \mathrm{H}_{2} \mathrm{O}$ (codificados após calcinação como MgO-1, MgO-3 e MgO-5 respectivamente) por $2 \mathrm{~h}$ com razão de aquecimento de 4 ${ }^{\circ} \mathrm{C} /$ min partindo da temperatura ambiente. Todos os óxidos gerados foram armazenados após sua síntese sob vácuo à temperatura ambiente até utilização no processo reacional (teste catalítico).

\section{Caracterização dos óxidos}

Os óxidos sintetizados foram caracterizados através de análise termogravimétrica, difração de raios-X (método do pó) e adsorção física de $\mathrm{N}_{2}$ conforme descrito a seguir.

A estabilidade térmica dos precursores foi monitorada em um termoanalisador Thermal Science modelo PL-STA, dotado de um forno com aquecedor e termobalança de compressão. As curvas TG foram obtidas com razão de aquecimento de $20 \%$ min a partir da temperatura ambiente até $1000{ }^{\circ} \mathrm{C}$, onde $20 \mathrm{mg}$ de amostra permaneceram por um período de $1 \mathrm{~h}$.

A confirmação da fase óxido foi realizada em difratômetro automático Philips modelo PW 300 empregando-se radiação monocromática de CuK $\alpha$; a análise foi executada utilizando-se uma tensão de excitação de $40 \mathrm{kv}$ e corrente no gerador de $40 \mathrm{~mA}$. A velocidade angular do goniômetro foi de $0,01^{\circ} / \mathrm{s}$ e intervalo de varredura de $2 \theta=20$ a $90^{\circ}$.

A área superficial específica e o volume de poros dos óxidos foram obtidos através da curva de adsorção física de nitrogênio em um analisador de adsorção gasosa Quantachome modelo NOVA 1200. Os resultados obtidos foram plotados pelos métodos Multi Point BET “adsorption” e BJH Cumulative Pore Size Distribution “desorption” respectivamente, onde foram utilizados $0,25 \mathrm{~g}$ de amostra nessa determinação. 


\section{Síntese dos ésteres (teste catalítico)}

O hexadecanoato de hexadecila obtido como teste catalítico foi preparado pela transesterificação do palmitato de metila com 1-hexadecanol conforme descrito a seguir, em três temperaturas de reações: 110,150 e $180{ }^{\circ} \mathrm{C}$ e variando a quantidade de catalisador ( $0 \%, 0,5 \%, 1,0 \%$ e $3 \%$ em relação a massa total dos reagentes).

Para síntese foi tomado um balão de fundo redondo de $125 \mathrm{~mL}$ de capacidade onde foram adicionados $1,00 \mathrm{~g}$ de palmitato de metila $\left(3,7 \times 10^{-3}\right.$ mols) e $1,79 \mathrm{~g}$ de 1 -hexadecanol (7,3 x 10-3 mols) este último em excesso; o balão foi mantido sob agitação e aquecimento até total fusão dos reagentes, em seguida foi adicionado à mistura reacional o catalisador previamente ativado [9]. Depois de adicionado o catalisador ao meio reacional, o sistema é mantido sob agitação e aquecimento, por um período de $6 \mathrm{~h}$, que é então filtrada a quente sob vácuo em placa de vidro sinterizada acoplado a um kitassato para recuperação do catalisador.

A purificação do éster é feita colocando-se o produto formado, após este atingir a temperatura ambiente e solidificar-se, em um béquer sob agitação com $80 \mathrm{ml}$ de metanol por um período de $2 \mathrm{~h}$ e posterior filtração a fim de se obter o produto desejado livre do excesso de álcool reagente.

\section{Caracterização dos ésteres sintetizados}

Os ésteres sintetizados foram caracterizados através de espectroscopia de absorção na região do infravermelho e RMN ${ }^{1} \mathrm{H}$ e ${ }^{13} \mathrm{C}$, cromatografia em camada delgada comparativa (CCDC) e ponto de fusão.

A espectroscopia de absorção na região do infravermelho foi realizada na região de 4000 a $400 \mathrm{~cm}^{-1}$ em um espectrofotômetro Perkin-Elmer modelo 16 Pc FT-IR com transformada de Fourier utilizando-se a técnica da pastilha de $\mathrm{KBr}$ (mistura de 1,5 mg de amostra para $20 \mathrm{mg}$ de $\mathrm{KBr}$ ).

A espectroscopia de $\mathrm{RMN}$ de ${ }^{1} \mathrm{H}$ e ${ }^{13} \mathrm{C}$, foram realizadas em espectrômetro Varian modelo GEMINI 300, utilizando clorofórmio deuterado para dissolução de $30 \mathrm{mg}$ de amostra a ser analisada em freqüências de 300 e 75 MHz, respectivamente.
O ponto de fusão foi tomado em aparelho Microquímica modelo MQAPF-307 que utiliza chapas de aquecimento e programador de temperatura.

A cromatografia em camada delgada foi realizada utilizando vapores de iodo para indicar a produção do éster, utilizando uma mistura de éter de petróleo e éter etílico como solvente de arraste.

\section{Resultados e discussão}

\section{Determinação da temperatura de calcina- ção dos precursores}

Como já mencionado no item 2.1, foram preparados um total de seis amostras de $\mathrm{MgO}$, a partir de três diferentes precursores. Estas podem ser dividas em dois conjuntos, um em que a temperatura de calcinação utilizada foi tomada da literatura [7, 9] e outro em que a mesma foi determinada a partir dos dados obtidos da curva TG.

A curva TG para o hidróxido de magnésio, Figura 1, mostra entre a temperatura ambiente até aproximadamente $300{ }^{\circ} \mathrm{C}$ uma gradual perda de massa em torno de $3 \%$, possivelmente devido à eliminação de água de hidratação e/ou adsorvida na superfície. Entre 300 e $400{ }^{\circ} \mathrm{C}$ temos a principal perda de massa para este composto, da ordem de $30 \%$, o que pode ser atribuído à liberação de uma molécula de água e formação do óxido de magnésio, suposição coerente com o cálculo estequiométrico e com os dados da literatura [9]. Com base nesta curva TG tomou-se como temperatura de calcinação a de $420{ }^{\circ} \mathrm{C}$ para a obtenção do $\mathrm{MgO}$ a partir do $\mathrm{Mg}(\mathrm{OH})_{2}$, portanto inferior aos $600{ }^{\circ} \mathrm{C}$ sugeridos na literatura.

A curva TG para o oxalato de magnésio, Figura 1, mostra duas perdas de massa bem definidas. A primeira entre 100 e $220^{\circ} \mathrm{C}$ de aproximadamente $25 \%$ sugere, conforme literatura [10] e cálculos estequiométricos a liberação de duas moléculas de água. A segunda entre 450 e $530{ }^{\circ} \mathrm{C}$, de aproximadamente $47 \%$, foi atribuída à liberação de $\mathrm{CO}$ e $\mathrm{CO}_{2}$ e a formação de MgO. Isso está de acordo com a literatura [11] e com os cálculos 
estequiométricos realizados. Portanto, a partir da curva TG determinou-se como $540{ }^{\circ} \mathrm{C}$ a temperatura de calcinação para este precursor, novamente abaixo da temperatura encontrada na literatura [7].

A curva TG para o hidroxicarbonato de magnésio, Figura 1, mostra três perdas de massa ocorrendo de forma consecutiva. Aproximadamente elas ocorrem no intervalo de 100 e $330{ }^{\circ} \mathrm{C}, 350$ a 450 ${ }^{\circ} \mathrm{C}$ e 450 e $520{ }^{\circ} \mathrm{C}$, respectivamente. Resultados similares foram encontrados por Koel et. al. [12]. Eles analisaram, por cromatografia gasosa capilar, os gases liberados em cada um desses passos. No primeiro, observaram perda da maior parte da água de hidratação e uma pequena quantidade de dióxido de carbono. No segundo, o principal gás liberado é o $\mathrm{CO}_{2}$ e o restante da água. No terceiro, somente $\mathrm{CO}_{2}$ é liberado. O produto final formado a $520^{\circ} \mathrm{C}$ é o $\mathrm{MgO}$, o que concorda com os cálculos estequiométricos realizados. Assim, novamente encontrou-se uma temperatura de calcinação menor que o proposto em outros trabalhos da literatura [9].
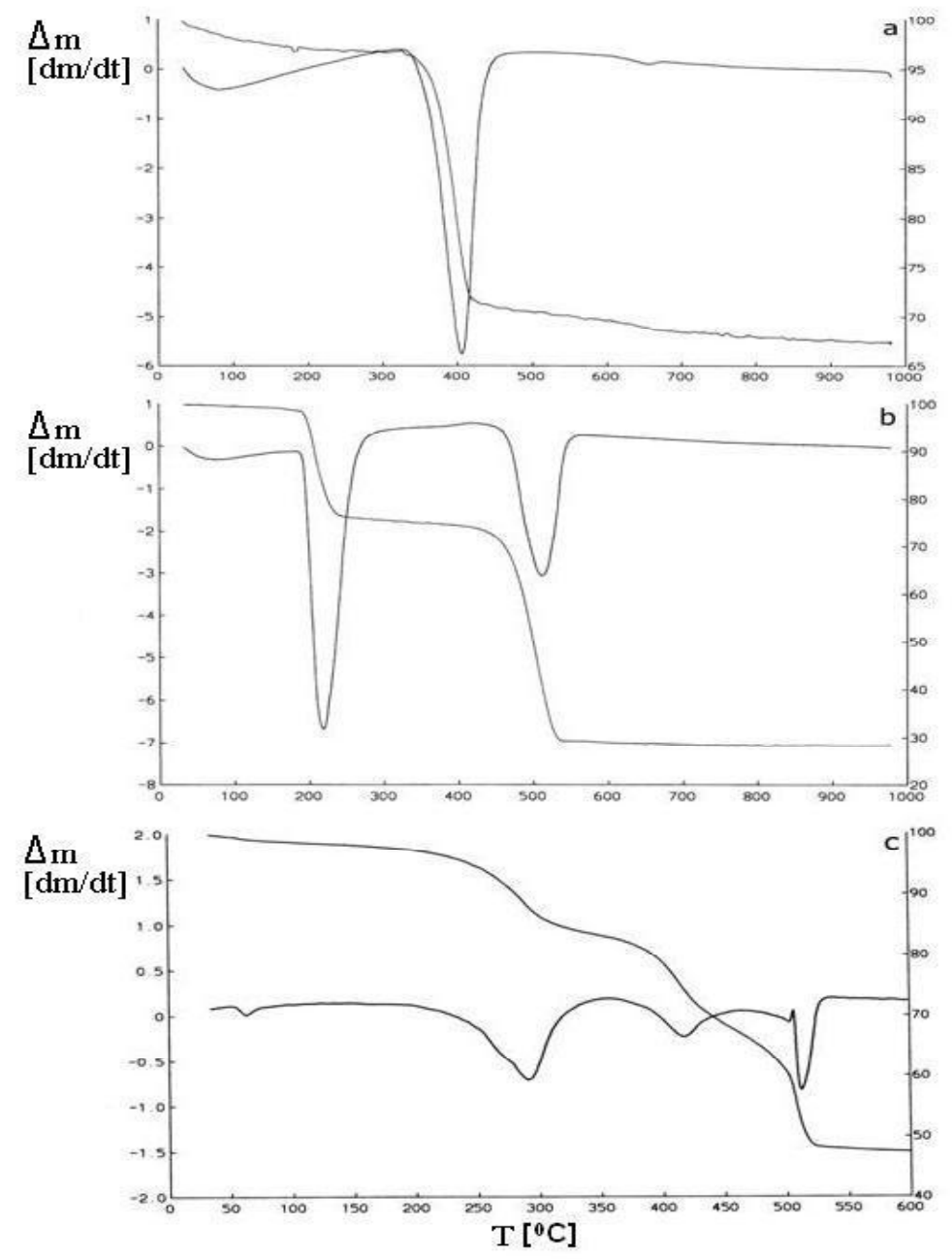

Figura 1. Curvas TG: (a) $\mathrm{Mg}(\mathrm{OH})_{2}$; (b) $\mathrm{MgC}_{2} \mathrm{O}_{4}$; (c) $\left(\mathrm{MgCO}_{3}\right)_{4} \cdot \mathrm{Mg}(\mathrm{OH})_{2} \cdot 5 \mathrm{H}_{2} \mathrm{O}$. 


\section{Caracterização dos óxidos}

A caracterização da formação do MgO para as seis amostras produzidas foi realizada por difração de raios $\mathrm{X}$. Os difratogramas de raios $\mathrm{X}$ pelo método do pó para os diversos óxidos sintetizados são virtualmente idênticos, assim somente um deles está mostrado na Figura 2. Todos exibem três picos característicos com d =2,44; 2,10 e $1,50 \AA$ ( $2 \theta=36,8 ; 43,0$ e 61,9, respectivamente) coerentes com a literatura [9] e outros dois com $d=1,50 ; 1,27 \AA$ ( $2 \theta=74,3$ e 78,4 respectivamente), que conferem com a indexação para um sistema cúbico, como mostrado na tabela 1.

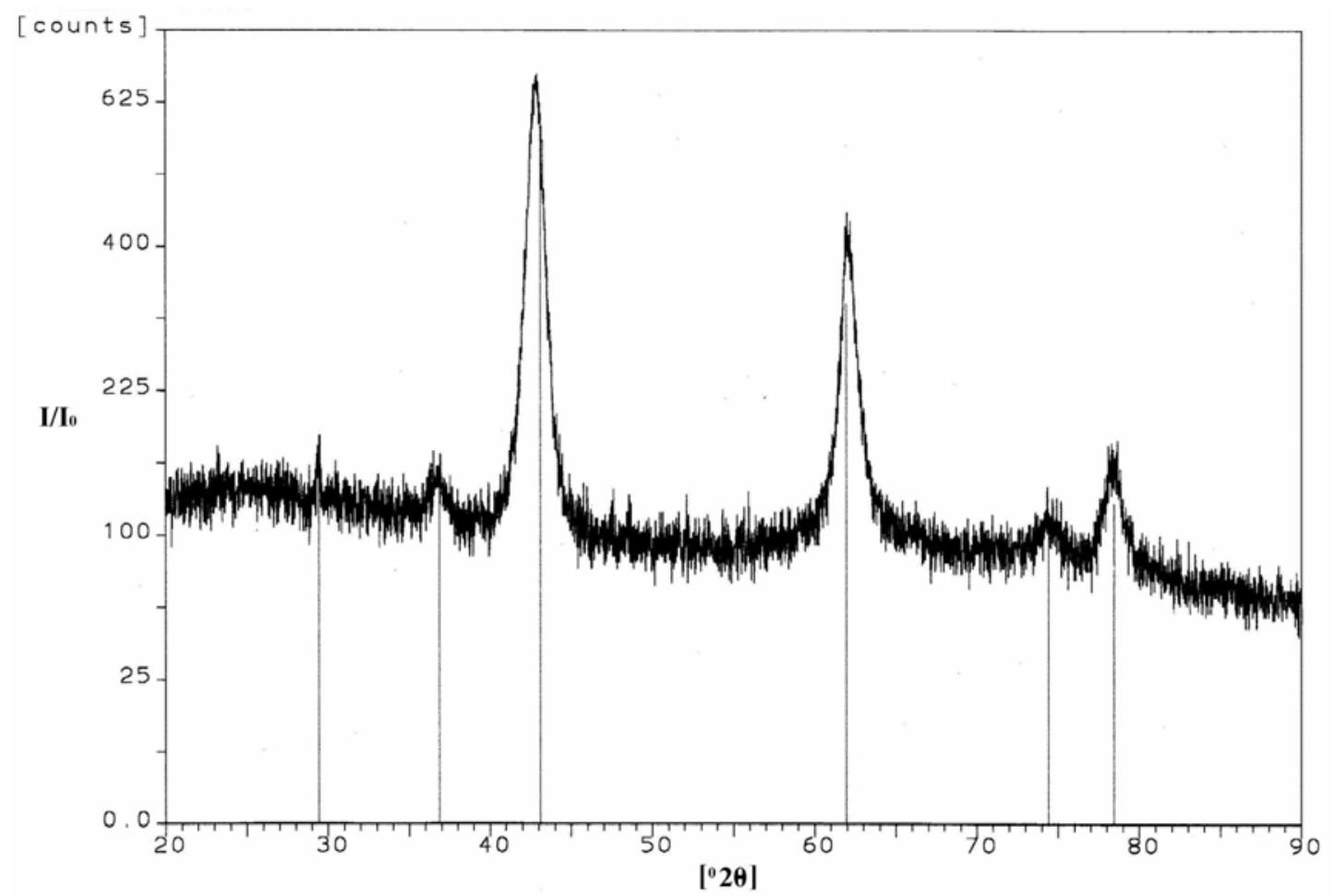

Figura 2. DRX (Método do Pó) para o MgO-1. Inserir Tabela 1

Tabela 1. Indexação e espaçamento $d$ para a amostra MgO-1.

\begin{tabular}{c|c|c|c|c}
\hline $\mathbf{2} \theta$ & $\mathbf{s e n}^{2} \boldsymbol{\theta}$ & Razão $\left(\boldsymbol{h}^{2}+\boldsymbol{k}^{\mathbf{2}}+\boldsymbol{l}^{2}\right)$ & \multicolumn{1}{c}{ Índices de Miller } & $\boldsymbol{d}(\boldsymbol{\AA})$ \\
\hline 36,835 & 0,099817 & 3 & 111 & 2,44 \\
43,090 & 0,134859 & 4 & 200 & 2,10 \\
61,930 & 0,264725 & 8 & 220 & 1,50 \\
74,395 & 0,365498 & 11 & 311 & 1,27 \\
78,405 & 0,399503 & 12 & 222 & 1,22 \\
\hline
\end{tabular}

A partir da relação entre o ângulo de difração e o parâmetro reticular obtido pela combinação da equação de Bragg com a expressão do espaçamento $d$ em função dos índices de Miller permite definir os parâmetros reticulares para o sistema cúbico $(a=b=c)$ através da equação 1 para as amostras ana- 
lisadas, pois no estado cristalino, os átomos estão arranjados em padrões que são caracterizados pela repetição periódica em três dimensões.

$$
\operatorname{sen}^{2} \theta=\frac{\lambda^{2}}{4 a^{2}}\left\{h^{2}+k^{2}+l^{2}\right\}
$$

Assim, temos que $a$ ficou em torno de 4,22 a 4,23 $\AA$ e como esperado é independente dos precursores e condições de síntese do óxido.

Desde que foi confirmada a formação do $\mathrm{MgO}$ pelo dados de difração de raios X, propriedades estruturais obtidas pela adsorção isotérmica de $\mathrm{N}_{2}$ foram medidas e estão resumidas na Tabela 2. Inicialmente pode-se notar a influência do precursor em tais propriedades. Tanto em um conjunto (formado pelos óxidos com temperatura de calcinação determinado pela termogravimetria, MgO-1, MgO-3 e $\mathrm{MgO}-5$ ) como no outro (calcinados a valores encontrados na literatura, $\mathrm{MgO}-2$, MgO-4, MgO-6), a influência do precursor sobre a área superficial específica, o diâmetro médio de poros e o volume total de poros, segue a seguinte ordem:

$$
\mathrm{Mg}(\mathrm{OH})_{2}>\mathrm{MgC}_{2} \mathrm{O}_{4}>\left(\mathrm{MgCO}_{3}\right)_{4} \cdot \mathrm{Mg}(\mathrm{OH})_{2}
$$

Outra tendência que se pode notar é a influência da temperatura de calcinação sobre tais propriedades. Ao se comparar amostras produzidas a partir dos mesmos precursores, nota-se que conforme a temperatura aumenta, há uma tendência em se produzir óxidos com áreas menores, porém com diâmetro médio e volume total de poros maiores.

\begin{tabular}{|c|c|c|c|c|}
\hline Amostra & Precursor & $\begin{array}{l}\text { Área específica } \\
\qquad\left(\mathrm{m}^{2} / \mathrm{g}\right)\end{array}$ & $\begin{array}{c}\text { Diâmetro dos } \\
\text { poros } \\
(\AA)\end{array}$ & $\begin{array}{l}\text { Volume de poros } \\
\text { (cc/g) }\end{array}$ \\
\hline $\mathrm{MgO}-1$ & $\mathrm{Mg}(\mathrm{OH})_{2}$ à $420^{\circ} \mathrm{C}$ & 141 & 264 & 0,93 \\
\hline $\mathrm{MgO}-2$ & $\mathrm{Mg}(\mathrm{OH})_{2}$ à $600^{\circ} \mathrm{C}$ & 115 & 399 & 1,15 \\
\hline MgO-3 & $\mathrm{MgC}_{2} \mathrm{O}_{4}$ à $540{ }^{\circ} \mathrm{C}$ & 117 & 159 & 0,46 \\
\hline $\mathrm{MgO}-4$ & $\mathrm{MgC}_{2} \mathrm{O}_{4}$ à $600{ }^{\circ} \mathrm{C}$ & 108 & 190 & 0,51 \\
\hline MgO-5 & $\left(\mathrm{MgCO}_{3}\right)_{4} \cdot \mathrm{Mg}(\mathrm{OH})_{2} \cdot 5 \mathrm{H}_{2} \mathrm{O}$ à $530^{\circ} \mathrm{C}$ & 82 & 130 & 0,26 \\
\hline MgO-6 & $\left(\mathrm{MgCO}_{3}\right)_{4} \cdot \mathrm{Mg}(\mathrm{OH})_{2} \cdot 5 \mathrm{H}_{2} \mathrm{O}$ à $650{ }^{\circ} \mathrm{C}$ & 51 & 159 & 0,20 \\
\hline
\end{tabular}

Tabela 2. Propriedades físicas dos óxidos a partir de diferentes precursores.

Testes catalíticos e caracterização dos ésteres sintetizados

Reações de transesterificação são reações em equilíbrio. A presença de água pode promover a hidrólise dos ésteres presentes com a formação de ácidos graxos. Por isso, nos vários testes da atividade catalítica do MgO frente à transesterificação do palmitato de metila com 1-hexadecanol que foram realizados, empregou-se sempre um excesso do álcool graxo, visando deslocar o equilíbrio no sentido dos produtos. Duas variáveis de processo foram investigadas: a concentração do catalisador e a temperatura da reação. Para se evidenciar a atividade do catalisador uma reação controle foi executada, ou seja, a reação foi desenvolvida na melhor condição de temperatura encontrada $\left(180^{\circ} \mathrm{C}\right)$, porém sem a presença de catalisador. O rendimento obtido foi de $18 \%$, e reflete somente o efeito da temperatura no rendimento da reação, como mostrado na Tabela 3.

Para exemplificar a influência destas duas variáveis, todos os experimentos executados para o catalisador MgO-1 estão igualmente apresentados na Tabela 3. Na menor temperatura $\left(110{ }^{\circ} \mathrm{C}\right)$, não se observa nenhuma reação ou o rendimento é muito baixo, independente de se aumentar a concentração do catalisador. Para a temperatura 
intermediária, há um aumento significativo no rendimento do produto, mas novamente, não se observa influência da quantidade de catalisador no processo. Para a maior temperatura $\left(180^{\circ} \mathrm{C}\right)$, há um aumento mais significativo quando se passa de 0,5 para $1 \%$ de catalisador, mas um aumento para $3 \%$ do mesmo não causou um maior rendimento. Assim, estabeleceu-se que, em relação a estes dois parâmetros, as melhores condições seriam temperatura de $180{ }^{\circ} \mathrm{C}$ e $1 \%$ de catalisador em relação à massa dos reagentes. Todos os outros testes visando verificar a influência do precursor sobre a atividade catalítica do $\mathrm{MgO}$ foram executados nestas condições, como resumido na Tabela 3.

Tabela 3. Estudo quantitativo da produção do hexadecanoato de hexadecila.

\begin{tabular}{|c|c|c|c|}
\hline Catalisador & $\begin{array}{c}\text { Condições } \\
\text { experimentais }\end{array}$ & $\begin{array}{c}\text { Quantidade de catalisador } \\
\qquad(\%) *\end{array}$ & $\begin{array}{c}\text { Rendimento da reação } \\
(\%)\end{array}$ \\
\hline sem catalisador & reação a $180^{\circ} \mathrm{C}$ & - & 18 \\
\hline MgO-1 & reação a $110^{\circ} \mathrm{C}$ & 0,5 & 00 \\
\hline MgO-1 & reação a $150^{\circ} \mathrm{C}$ & 0,5 & 52 \\
\hline MgO-1 & reação a $180^{\circ} \mathrm{C}$ & 0,5 & 53 \\
\hline MgO-1 & reação a $110^{\circ} \mathrm{C}$ & 1 & 9 \\
\hline MgO-1 & reação a $150^{\circ} \mathrm{C}$ & 1 & 49 \\
\hline MgO-1 & reação a $180^{\circ} \mathrm{C}$ & 1 & 60 \\
\hline MgO-1 & reação a $110^{\circ} \mathrm{C}$ & 3 & 00 \\
\hline MgO-1 & reação a $150^{\circ} \mathrm{C}$ & 3 & 50 \\
\hline MgO-1 & reação a $180^{\circ} \mathrm{C}$ & 3 & 60 \\
\hline MgO-2 & reação a $180^{\circ} \mathrm{C}$ & 1 & 63 \\
\hline MgO-3 & reação a $180^{\circ} \mathrm{C}$ & 1 & 67 \\
\hline $\mathrm{MgO}-4$ & reação a $180^{\circ} \mathrm{C}$ & 1 & 77 \\
\hline MgO-5 & reação a $180^{\circ} \mathrm{C}$ & 1 & 76 \\
\hline MgO-6 & reação a $180^{\circ} \mathrm{C}$ & 1 & 72 \\
\hline
\end{tabular}

*Em relação à massa de reagentes total empregada.

É comum que catalisadores mostrem uma maior atividade quanto maior a área superficial específica. Ainda, considerando-se que os reagentes envolvidos são constituídos por moléculas muito volumosas seria de se esperar que poros maiores também favorecessem tal atividade. Não é o que é observado nos testes apresentados. De maneira geral, os óxidos de menores áreas e diâmetros de poros mostram as maiores conversões, por isso, a atividade catalítica deve ocorrer na superfície do óxido. Esta aparente contradição pode ser explicada considerando o grau de acidez e basicidade de Lewis. Os caráteres ácido e básico do MgO estão associados respectivamente ao cátion $\mathrm{Mg}^{2+}$ e ao ânion $\mathrm{O}^{2-}$, com números de coordenação menores que os encontrados normalmente $(6,6)$ nesse óxido [9, 13]. Assim, quanto maior o número de defeitos estruturais na superfície, maior o grau de acidez/basicidade e espera-se uma maior conversão. Embora não tenham sido executadas medidas do grau de basicidade superficial, provavelmente pelos resultados encontrados elas sejam diretamente influenciadas pelo precursor na seguinte ordem:

$\mathrm{Mg}(\mathrm{OH})_{2}>\mathrm{MgC}_{2} \mathrm{O}_{4}>\left(\mathrm{MgCO}_{3}\right)_{4} \cdot \mathrm{Mg}(\mathrm{OH})_{2}$ Essa é uma suposição razoável considerando que isto é uma tendência geral e todas as outras variáveis do processo são mantidas constantes.

O desenvolvimento da reação e a purificação do produto foram acompanhados por cromatografia em camada delgada comparativa (CCDC). Após a purificação, o produto foi analisado por CCDC e RMN de ${ }^{1} \mathrm{H}$ e ${ }^{13} \mathrm{C}$. A análise por CCDC não detectou qualquer contaminação do produto pelos reagentes, mostrando uma única mancha revelada pelo iodo, referente ao hexadecanoato de hexadecila. No espectro de ${ }^{1} \mathrm{H}$ não se detectou a 
presença de sinais que seriam característicos dos reagentes: para o hexadecanol, um tripleto próximo a 3,5 ppm que seria esperado para os dois hidrogênios pertencentes ao grupo que contem a função álcool; para o hexadecanoato de hexadecila, um singleto próximo a 2,1 ppm que seria esperado para os hidrogênios do grupo $-\mathrm{CH}_{3}$ terminal. No espectro de ${ }^{13} \mathrm{C}$ destacamos a ausência de um sinal próximo a 210 ppm que indicaria a presença do hexadecanoato de hexadecila.

Já a solução de lavagem mostrou tanto a mancha referente ao reagentes como ainda uma pequena mancha referente ao hexadecanoato de hexadecila, pois o mesmo é parcialmente solúvel em metanol. Isso indica que um sistema solvente mais adequado para a purificação provavelmente aumentaria os rendimentos obtidos neste trabalho.

\section{Caracterização do hexadecanoato de hexa- decila}

Após a purificação do produto, a confirmação do seu grau de pureza foi avaliada determinando-se o ponto de fusão para várias frações. Todos os resultados obtidos situaram-se entre 53,1 e 53,3 ${ }^{\circ} \mathrm{C}$, muito próximo ao valor relatado na literatura, que é de $54{ }^{\circ} \mathrm{C}$ [14], evidenciando a homogeneidade e mais uma vez a pureza do produto.

O sucesso da síntese foi avaliado pela identificação estrutural do éster. Tal identificação foi efetuada por espectroscopia de absorção na região do infravermelho e RMN de ${ }^{1} \mathrm{H}$ e ${ }^{13} \mathrm{C}$.

No espectro na região do infravermelho, como esperado para um éster de cadeia longa, se destacam as bandas devido aos estiramentos $\mathrm{C}-\mathrm{H}$ assimétricos e simétricos (2918 e $2849 \mathrm{~cm}^{-1}$ respectivamente) e as deformações angulares dos grupos - $\mathrm{CH}_{2}$ - das cadeias carbônicas; os estiramentos $\mathrm{C}=\mathrm{O}\left(1732 \mathrm{~cm}^{-1}\right)$ e $\mathrm{C}-\mathrm{O}\left(1183 \mathrm{~cm}^{-1}\right)$ da função éster e uma banda muito característica devido a uma oscilação dos grupos $-\mathrm{CH}_{2}-\left(723 \mathrm{~cm}^{-1}\right)$ em cadeias longas.

No espectro de ${ }^{1} \mathrm{H}$ destacam-se três tripletos centrados em 0,88; 2,28 e 4,05 ppm devido aos hidrogênios dos grupos $-\mathrm{CH}_{3}$ terminais, aos do grupo $-\mathrm{CH}_{2}$ - vizinho à carbonila e aos do grupo $-\mathrm{OCH}_{2}$-, respectivamente, além de um sinal muito mais intenso em 1,25 ppm devido aos demais grupos $-\mathrm{CH}_{2}$ - das cadeias carbônicas.

No espectro de ${ }^{13} \mathrm{C}$ o sinal a 173,9 ppm é devido ao carbono da carbonila, o sinal em 64,3 ppm ao C ligado ao oxigênio da função éster, o sinal em 34,4 ppm ao carbono vizinho à carbonila, e o sinal em 14,0 ppm devido ao carbono dos grupos $-\mathrm{CH}_{3}$ terminais.

A reunião de todas essas informações mostra claramente o sucesso da rota de síntese e a obtenção dos produtos com elevada pureza, que foi o objetivo principal do presente estudo.

\section{Conclusão}

Após a execução desta pesquisa pode-se destacar o seguinte:

1 - A atividade do catalisador $\mathrm{MgO}$ fica evidente quando se compara o rendimento de 18\% para a reação de síntese do hexadecanoato de hexadecila sem sua presença com o rendimento mínimo de 52\% quando se utiliza o MgO-1, isto acontecendo fora da temperatura ideal de reação $\left(180{ }^{\circ} \mathrm{C}\right)$. Junto com o catalisador a temperatura de reação é um fator de importância destacada, na conversão dos reagentes em produtos, pois um aumento de $110^{\circ}$ para $180^{\circ} \mathrm{C}$ propicia uma melhora significativa no rendimento do processo. Demonstrou-se ainda que $1 \%$ de catalisador é a quantidade adequada para obter-se um rendimento máximo dentro das condições experimentais estipuladas.

2 - Através dos parâmetros físicos analisados (área específica, diâmetro e volume de poros), o precursor influencia diretamente nas características do óxido de magnésio, tanto que comparando-se o MgO-1 obtido a partir do hidróxido de magnésio com o MgO-4 obtido a partir do oxalato de magnésio, ambos empregados nas mesmas condições reacionais, o primeiro apresentou um rendimento de $60 \%$ enquanto que o segundo apresentou um rendimento de $77 \%$. Porém, também é comprovada através do rendimento reacional que não é o óxido com os maiores valores destas propriedades que são responsáveis pela maior atividade na reação, talvez sim outros fatores superficiais que possam estar acontecendo como a distribuição da acidez e basicidade decorrentes da 
criação de defeitos estruturais em função do tratamento térmico imposto ao precursor, comprovando por este motivo que a escolha do precursor é um fator primordial na obtenção do óxido.

3 - Da mesma forma que a escolha do precursor apresenta um papel importante na obtenção do catalisador com propriedades que podem intensificar o rendimento em um processo, a temperatura em que o precursor é tratado termicamente também contribuí para obtenção do óxido com diferentes valores das propriedades físicas citadas anteriormente.

Received November 032008

Accepted October 232009

ABSTRACT: A long chain ester was prepared by transesterification of methyl palmitate with long chain alcohol using magnesium oxide as catalyst prepared by thermal decomposition of different precursors with the intention of establish relations among structural properties and activities. Temperature and catalyst amounts were modified in order to evaluate the yield of the ester in function the precursors used in preparation of the oxide.

Keywords: transesterification, long chain esters and magnesium oxide.

\section{Referências}

[1] K. Tanabe, W. F. Hölderich, Appl. Catal. A, General 181 (1999) 399.

[2] H. Hattori, M. Shima, H. Kabashima, Stud. Surf. Sci. Catal. 130 (2000) 3507.

[3] T. F. Dossin, et al., Appl. Catal. B, Environmental 67 (2006) 136.

[4] C. Lacaze-Dufaure, Z. Mouloungui, Appl. Catal. A, General 204 (2000) 223.

[5] S. Siler-Marinkovic, A. Tomasevic, Fuel, 12 (77) (1998) 1389.

[6] N. Sánchez, et al., JAOCS 11 (69) (1992) 1150.

[7] H. Kabashimaa, et al., Appl. Catal. A, General 165 (1997) 319.

[8] A. Corma, et al., J. Catalysis 173 (1998) 315.

[9] M. A. Aramendia, V. Borau, et al., J. Mater Chem. 6 (12) (1996) 1943.

[10] W. W. Wendlandt, Thermal Analysis, John Wiley \& Sons, New York, 3rd edn., 1986, p. 149 - 150.

[11] El-H. M. Diefallah, et. al., J. Analyt. Appl. Pyrol. 62 (2002) 205.

[12] M. Koel, et. al. Therm. Acta 322 (1998) 25.

[13] V. R. Choudhary, V. H. Rane, R. V. Gadre, J. Catalysis 145 (1994) 300.

[14] M. Windholz, The Merck Index. USA: MERCK \& CO., 1983. 